\title{
EVOLUCIÓN DE LA POBLACIÓN ESCLAVA A TRAVÉS DE LAS CÉDULAS REALES CONCEDIDAS A LA FAMILIA PONCE DE LEÓN EN EL PUERTO RICO DEL SIGLO XVI
}

\author{
EVOLUTION OF THE SLAVE POPULATION \\ THROUGH THE ROYAL CEDULES GRANTED TO THE \\ PONCE DE LEÓN FAMILY IN THE PUERTO RICO OF \\ THE 16TH CENTURY
}

\author{
TAMARA IÁÑez Ramírez*
}

Universidad de Granada

\section{RESUMEN}

La llegada de los colonizadores a las islas del Caribe fue un hito en la historia. Influyó en la forma en la que percibimos el mundo en la actualidad. La forma en la que la isla de San Juan Bautista (Puerto Rico) fue colonizada ayuda a comprender como se fue modificando el sistema de producción, recayendo una gran parte en la mano de trabajo esclava. Una de las forma de percibirlo es el análisis de las diferentes fuentes archivísticas que hacen mención a que personas eran las encargadas de realizar este trabajo. Siendo una de las familias más importantes la de Ponce de León que junto a otras personalidades sustentaron un modelo esclavista, cuya huella, todavía hoy día, sigue patente.

Palabras clave: Puerto Rico, familia Ponce de León, siglo XVI, esclavitud.

\section{ABSTRACT}

The arrival of the colonizers on the Caribbean islands was a milestone in history. It influenced the way we perceive the world today. The way the island of San Juan Bautista (Puerto Rico) was colonized helps to understand how the production system was modified, with a large part in the slave work. One of the ways of perceiving it is the analysis of the different archival sources that mention which people were in charge of doing this work. One of the most important families being that of Ponce de León who together with other personalities supported a slavery model, whose footprint, even today,

Keywords: Puerto Rico, Ponce de León family, 16th c., Slavery.

*Licenciada en Historia por la Universidad de Granada, graduada en Antropología Social y Cultural por la Universidad de Granda y con un Máster en Arqueología por la Universidad de Granada. 


\section{RESUM}

\section{LA POBLACIÓ ESCLAVA SEGONS LES CÈDULES REALS CONCEDIDES A LA FAMÍLIA PONCE DE LEÓN AL PUERTO RICO DEL SEGLE XVI}

L'arribada dels colonitzadors a les illes del Carib va ser una fita en la història, puix va influir en la forma que percebem el món en l'actualitat. La manera que I'illa de Sant Joan Baptista (Puerto Rico) va ser colonitzada ajuda a comprendre com es va modificar el sistema de producció, recaient una gran part a la mà de treball esclava. Una de les formes de percebre-ho és I'anàlisi de les diferents fonts arxivístiques que esmenten quines persones eren les encarregades de fer aquest treball. Sent una de les famílies més importants la de Ponce de León que junt amb altres personalitats sustentaren un model esclavista $\mathrm{i}$ han deixat una petjada que, avui dia, segueix patent.

Paraules clau: Puerto Rico, família Ponce de León, segle XVI, esclavitud. 


\section{INTRODUCCIÓN}

La isla de Puerto Rico durante el siglo XVI tiene una población compleja que va evolucionando a lo largo de las primeras décadas. Este artículo se va a centrar en una parte muy concreta: la población esclava. Conformada ya sea por personas que fueron sometidas provenientes de la isla de San Juan, de otras islas del Caribe, traídas desde la Península lbérica o desde el continente africano. Para hacer posible este artículo he llevado a cabo una revisión bibliográfica y poder así abordar esta cuestión en particular. Añadiendo a esto el análisis y estudio de una serie de documentos archivísticos que pueden dar una serie de pautas sobre cómo evolucionó el tipo de personas que engrosaban esta parte de la población de la isla. Una de las principales problemáticas al abordar este tema, y que hay que tener en cuenta, es que en muy poco tiempo la forma en la que se nutren de población esclava va cambiando de forma muy rápida. Por lo que responder a la cuestión del por qué ocurre es complicada. Ya que la respuesta no es única, sino que pueden existir multitud de ellas. Otra de las cuestiones a responder es si en este proceso de cambio se puede vislumbrar el porqué del inicio de un tráfico esclavista que se nutría del África subsahariana y que se convirtió en un tráfico global.

Todas estas cuestiones no se pueden abordar si no se tiene cuenta, desde un primer momento, la importancia de la esclavitud como un sistema de producción a lo largo del siglo XVI. Siendo un sistema, que aunque estaba en un momento de decadencia en la Península Ibérica, se había trasladado a las islas del Caribe cómo único método plausible para satisfacer las necesidades productivas. Lo importante de esta afirmación, es que la esclavitud, tanto en España como en Europa, era una realidad. Este axioma nos ayuda a colocarnos en un contexto, tanto histórico como social, político y 
económico que se aleja de nuestra realidad actual. Lo que nos ayuda a abordarlo con cierta perspectiva histórica necesaria para no caer en prejuicios morales y éticos.

Otro de los aspectos a tener en cuenta para comprender la importancia de Puerto Rico en la historia de la esclavitud en el Caribe, es su posición en dicho mar. Lo que condiciona sobre manera la historia de su colonización. Para atisbar este proceso he decidido centrarme en una familia que tuvo una gran relevancia histórica en la colonización de la isla de Puerto Rico, la de Ponce de León. Teniendo como epicentro de este análisis las diferentes Cédulas Reales que se concedieron a lo largo de los años, dónde se hace hincapié en las encomiendas relacionadas con la esclavitud, ya sea sobre la población autóctona de la isla de San Juan, de otras islas del Caribe, de personas traídas de la Península lbérica o de África.

\section{Esclavitud y sistema esclavista duRante la Edad Moderna en España}

Lo primero que voy a abordar es cual fue la importancia de la esclavitud en España. Algo esencial para poder comprender como este sistema tuvo una gran acogida, siendo pensado como el único para obtener una producción de la isla. Lo que se implementa en la isla no es otra cosa que el reflejo de lo que había en Europa a lo largo de la Edad Moderna. La esclavitud era un sistema normalizado dentro del marco europeo, así como en España. Según los prejuicios actuales se hace imposible aceptar la idea de que la esclavitud era una realidad en el siglo XVI. Y lo más importante, que era un sistema reconocido de forma generalizada, el cual se percibía por parte de la sociedad, el Estado y la Iglesia Católica como algo valido y aceptable.' Un sistema que se convirtió en algo imprescindible para los Reinos de Castilla y Aragón de la Península lbérica en el siglo XVI, un elemento para controlar a la población, para implementar medidas civilizadoras, evangelizadoras y productivas. ${ }^{2}$ Ya no solo en la Península lbérica sino también en las islas del Caribe.

Para llegar a entender la importancia de la mano de obra esclava en los Reinos de la Península Ibérica, sobre todo en el Reino de Castilla, hay que tener en cuenta que, aunque la economía no descansa de forma total en

1 MARTÍN CASARES, Aurelia. (2000). La esclavitud en la Granada del Siglo XVI. Universidad de Granad, Granada.

2 BUGANZA, Jacob (2006), "La Otredad o Alteridad en el Descubrimiento de América y la Vigencia de la Utopía Lascasiana", Razón y Palabra, n 54. 
la mano de trabajo esclava, es decir, no podemos considerarla como una "sociedad esclavista", sí tiene una gran importancia. ${ }^{3}$ Es decir, el mundo moderno incipiente de finales del siglo XV, tiene una economía imposible de subsistir sin dichas personas esclavas. ${ }^{4}$ Es por ello que existe una necesidad imperante por parte de estos reinos cristianos de hacerse con esclavos y esclavas, ya que eran un elemento necesario para que el sistema de producción no colapsase. ${ }^{5} \mathrm{Y}$ aunque era un sistema que estaba en vías de desaparecer, la llegada de los reinos cristianos a las islas del Caribe lo refuerza. ${ }^{6}$ En un primer momento, durante la Edad Media, las principales personas esclavizadas son de la propia Península lbérica. Personas que eran capturadas mediante las guerras y razias entre los reinos pertenecientes a la fe cristiana y fe musulmana. Esto dejó de producirse ya que en 1492 no existían tierras bajo el dominio musulmán. También se benefician los reinos cristianos de las gentes de las islas Canarias, los guanches, algo que al poco tiempo se prohíbe ya que eran personas que habían sido evangelizadas, y por las revueltas y rebeliones en las Alpujarras, en Granada, entre 1568 y 1570 . También existía un comercio con Italia que suministraba personas del Mar Negro. Algo que cambia a finales del siglo XV ya que pierde el control de esta zona en beneficio del Imperio Ruso.?

En el imaginario colectivo parece imperar en la creencia popular que la esclavitud en la Península lbérica no existía y que con la llegada de la modernidad se presupone la extinción de la esclavitud como sistema productivo. Cuando la esclavitud fue un sistema que estuvo vivo hasta finales del siglo XIX. Un sistema que permitió la colonización efectiva de las tierras del Caribe y de la tierra firme de America.

Como constancia de ello son la multitud de artículos, libros y estudios que se han centrado en la esclavitud tanto en la Península Ibérica como en otras partes de Europa como por ejemplo Francia e Italia durante la Edad Moderna y hasta siglo XIX. ${ }^{8}$

3 MARTÍN CASARES, La esclavitud en la Granada del Siglo XVI.

4 MINGORANCE, José Antonio y ABRIL, José María, (2013), La esclavitud en la Baja Edad Media. Jerez de la Frontera. 1392-1550, PeripeciasLibros, Madrid.

5 FRANCO SILVA, Alfonso, (1992), Esclavitud en Andalucía (1450-1550), Universidad de Granada, Granada.

6 PHILLIPS, William. D. (1989), La esclavitud desde la época romana hasta los inicios del comercio transatlántico. Siglo XXI, Madrid.

7 PHILLIPS, La esclavitud desde la época romana.

8 FRANCO SILVA, Alfonso, (1995), "La esclavitud en la península ibérica a finales del Medievo. Estado de la cuestión y orientaciones bibliográficas", Medievalismo. Boletín de La Sociedad Española de Estudios Medievales, n6, pp. 201-210. 


\section{Puerto Rico: contexto geográfico e histórico}

El lugar en el que centra esta investigación es la isla de Puerto Rico, situada en el mar Caribe. La más pequeña de las Antillas mayores, y en una de las primeras islas en las que llegaron los barcos de los primeros colonizadores. Esta posición geográfica influirá de forma contundente en el devenir histórico de dicha isla, no solo en su pasado, sino en su presente más inmediato, ya que es la isla que da entrada al mar Caribe, y al resto del continente Americano.

La isla de Borinquen, nombre con la que se identificaba a la isla de Puerto Rico en época taína, antes de la llegada de los pobladores españoles, fue descubierta por Colón en su segundo viaje en 1493, más concretamente el 25 de septiembre. Esta expedición se dirigía a La Española donde había abundante oro y riquezas. A esta isla la bautizaron con el nombre de San Juan Bautista. ${ }^{9}$ Y no fue hasta casi 15 años después cuando se produjo la colonización de la isla. ${ }^{10} \mathrm{El}$ momento en el cual a Colón ya se le habían retirado sus derechos sobre la colonización y explotación del Nuevo Mundo. La persona encargada de llevar a cabo la colonización efectiva de la isla fue Juan Ponce de León, en el año 1508 con el beneplácito de los Reyes Católicos y el gobernador general Frey Nicolás Ovando. Para hacer efectivo el control de la isla, Juan Ponce de León se puso en contacto con los caciques de la isla. A estos caciques se les concedió tierras e indios en propiedad para que las produjesen.

Es así como comenzó un sistema muy parecido al que existía en ese momento en la isla de La Española. La población que habitaba en estas islas, junto con las tierras, se repartieron entre los caciques autóctonos de la isla, y los colonizadores, entre los que se contaba Juan Ponce de León. Esta poblacion autóctona trabajaba de forma forzosa en las minas de oro para el beneficio de la Corona y en las tierras que se repartieron entre los colonizadores y caciques. ${ }^{11}$

La población de la que se nutrió el sistema esclavista en la isla de San Juan Bautista fue cambiando a lo largo de los años de forma rápida y constante, sobre todo en las primeras décadas del siglo XVI. Este sistema se sustentó de personas tanto de dentro como de fuera de la isla.

9 PICÓ, Fernando, (1990), Historia general de Puerto Rico, Ediciones Huracán, Río Piedras.

10 DÍAZ SOLER, Luis Manuel, (1950), Historia de la esclavitud negra en Puerto Rico (1493-1890), Lousiana State University Press / Universidad de Puerto Rico, San Juan.

11 PICÓ, Historia general de Puerto Rico. 


\section{Evolución del sistema esclavista en la isla de San Juan Bautista}

En la isla de San Juan Bautista se puede apreciar cómo ha ido cambiando en el siglo XVI la procedencia de las personas que eran esclavizadas, o que eran utilizadas como mano de obra que sustentaba este sistema esclavista. Lo que nos va dando información del devenir histórico de la propia isla y de los reinos peninsulares en cuanto a conflictos como a relaciones políticas y religiosas.

\section{Población taína y caribes}

En estas dos primeras décadas la población que se utilizó para sostener la producción de la isla de San Juan Bautista fueron tanto los taínos, población autóctona de la isla, como los caribes, que habitaban las islas del este del Caribe, así como las costas de Venezuela. Se estima, según estudios llevados a cabo, que había entre los años 1508 y 1520 unos 60.000 y 125.000 indios taínos y caribes. ${ }^{12}$

La población que vive en la isla de Puerto Rico es la denominada como taína, diferenciándola de los caribes. Rouse pone sobre la mesa que estos dos términos separan a los taínos y los caribes entre las diferentes islas del Caribe. ${ }^{13}$ Los taínos serían aquellos que habitaban en las Antillas mayores, mientras que los caribes se encontrarían en las Antillas menores y costas de Venezuela. También se impondría una creencia entre estas dos poblaciones, y es considerar la población taína más sumisa y fácil de someter. Mientras tanto, los caribes serían aquellos considerados los más agresivos, caníbales y menos propensos a dejarse subyugar por las autoridades colonizadoras. Era una forma de diferenciar entre aquellos que eran más fáciles de controlar y aquellos que eran rebeldes y luchaban por su libertad. ${ }^{14}$ En estos primeros años de contacto, se percibe una disminución de la población autóctona de la isla. Esto se debe a varias causas, una de ellas es por la multitud de enfermedades que traen los colonizadores no siendo inmune esta población y por tanto sucumbiendo a la muerte. Otra de las causas es la insuficiencia en la alimentación, que llevó a las poblaciones

12 MOSCOSO, Francisco (2005), "Población del siglo XVI", en Tras las huellas del hombre y la mujer negros en la historia de Puerto Rico. Antología de lecturas, Departamento de educación de Puerto Rico, San Juan, , (pp. 262-264).

13 ROUSE, Irving, (1992). The Tainos: rise \& decline of the people who greeted Columbus, New Haven, Yale University Press.

14 WHITEHEAD, Neil. L. (1995), "Ethnic plurality and cultural continuity in the native Caribbean: Remarks and uncertainties as to data and theory", Wolves from the Sea, pp. 91-111. 
autóctonas de la isla a menguar de forma rápida. Son varios los autores que opinan que a esto hay que añadir la represión a la que fueron objeto por parte de los colonos. ${ }^{15}$ Aunque los documentos que hacen referencia a una represión explícita contra las poblaciones de las islas del Caribe, únicamente hacen mención a los caribes. El documento que muestro a continuación en el que se hace referencia a como se pone a Juan Ponce de León a la orden de una armada para reprimir las acciones violentas que están llevando a cabo los caribes. ${ }^{16}$

"Nuestros oficiales de la Casa de Contratación de las Indias, que residís en la ciudad de Sevilla: Ya sabéis, como otras veces os he escrito, la mucha necesidad que hay que la armada que hemos mandado hacer contra los caribes vaya lo más presto que ser pueda, y porque mandamos ir por capitán de ella a Juan Ponce de León $[. . .]^{\prime \prime} .^{17}$

Aquí se hace referencia a cómo la población que se ha revelado contra las autoridades coloniales son los caribes. Esto, como ya he mencionado con anterioridad, puede llevar a error a la hora de saber que poblacion y que islas son las que se han rebelado. Al hablar de caribes, parece que no se hace referencia a los habitantes de la isla de Puerto Rico, y que eran poblaciones más agresivas que no tenían nada que ver con los taínos. Un pueblo que luchó con fuerza y de forma feroz para echar de sus tierras a los invasores y opresores. Pero también se ha expuesto que estos términos pueden ser vistos como una construcción ideológica, entorno a la creencia de que los más sumisos y pasivos fuesen los taínos, mientras que los más agresivos se les denominaba como caribes. Una construcción académica y social para dar una respuesta al por qué unas poblaciones eran fáciles de someter mientras que otras eran insubordinados y rebeldes. ${ }^{18}$ Por lo que, a lo mejor, estas revueltas se produjeron en la isla de Borinquen pero se asumió por las autoridades coloniales que fuereon producidas por las poblaciones caribes y dando por imposible que fuesen los taínos los causantes de estas escaramuzas.

15 DÍAZ SOLER, Luis María. (1953). Historia de la esclavitud en Puerto Rico, Editorial de la Universidad de Puerto Rico, San Juan.

16 PICÓ, Historia general de Puerto Rico.

17 Real Cédula, (1531), Archivo General de Indias (AGI), Santo Domingo, 2280, L. 1, F.90V-91R.

18 ROUSE, The Tainos: rise \& decline of the people who greeted Columbus. 
Existen varios documentos en los que se hace referencia a los caribes como una población difícil de someter y agresivos. En estos documentos se hace referencia a la guerra que se estaba llevando contra estas poblaciones y como a través de su venta se estaba financiando estas contiendas.

"De los caribes que se cautivaren de buena guerra habéis de enviar a la isla Española a los nuestros oficiales, que en ella residen, las dos tercias partes dellos, para que los vendan en nuestro nombre, y de los que ellos hubiere, sirve para ayuda a gastos de la dicha armada, y la otra tercia parte dellos habéis de repartir entre la gente que con vos fuere en la dicha armada, para que los vendan y se aprovechen dellos como de cosa suya, porque con darles la tercia parte de los esclavos que hubieren, se excusen el sueldo que se haya de dar $[\ldots]^{\prime \prime} .^{19}$

Este es un ejemplo perfecto de que estos indios caribes eran capturados en la guerra, se vendían como esclavos y se entregaban como pago a la gente que participaba y guerreaba bajo el estandarte de la Corona de Castilla. Durante los primeros años del siglo XVI estos se convirtieron en la principal mano de obra esclava, para sacar de la isla el poco oro que había. Junto a estos caribes, tal y como son nombrados en los documentos históricos, también se pueden encontrar a los taínos. Poblacion de la isla de Puerto Rico, y que no podían ser tratados como esclavos ya que en los primeros años de la colonización se dejó estipulado que estas personas no podían ser tratadas como esclavas. Por el contrario solo sufrirían esta falta de libertad durante un periodo de tiempo determinado.

Una de las primeras medidas que se llevaron a cabo fueron los Repartimientos de Indios, mediante los cuales se repartían a los indios siendo los principales beneficiarios tanto colonos como caciques naturales de la isla.

"Don Fernando, etc., por cuanto visto por el Concejo los privilegios que yo y la serenísima Reina, $D^{a}$ Isabel, mi mujer [...] hebemos proveído de mandar enviar personas para que de nuevo hagan el repartimiento en la dicha isla de San Juan, porque el que estaba hecho della no es tan igual ni justo como a nuestro servicio y al bien y provecho de los vecinos y moradores y otras personas de la dicha isla convenía 
[...] hayais información por todas partes y maneras que mejor pudiereis saber qué caciques e indios y naborios hay en dicha isla de San Juan para poder repartir $[\ldots]^{\prime \prime}{ }^{20}$

En este fragmento de un texto escrito en el año 1514 podemos observar cómo estos repartimientos de indios se hacían entre los vecinos que así lo merecen de la isla a Juan Ponce de León. Pero existe un aspecto que llama poderosamente la atención, un concepto, el cual hace referencia a la población india de la isla de San Juan, naboría. Estos naboríos hacen alusión al repartimiento de los indios entre los vecinos de la isla, pero con la particularidad de que estos indios solo estarían bajo su servicio durante un periodo determinado de tiempo. Pasado estos años estas personas debían ser liberadas. Es por tanto que no pueden ser considerados como población esclava en el más estricto sentido de la palabra. Eran personas que estaban sometidas durante un periodo de tiempo concretado con anterioridad.

"Adelantado Juan Ponce de León, nuestro capitán de la isla de San Juan,: Vi o que escribistes, que en las islas de los caribes hay muchos indios e indias naturales de la dicha isla de San Juan, que algunos han llevado cautivos los dichos caribes, y otros de su voluntad que han ido con ellos, y porque yendo vos, como placiendo a Nuestro Señor habéis de ir con nuestra armada a hacer guerra a los dichos caribes, creéis que muchos de los indios se vendrán de su voluntad a vos [...] mandase declarar para si serían libres o cautivos, lo cual visto parece que viniéndose los dichos indios de su voluntad a vos, y a la gente que con vos va en esta armada a nuestro ser vicio y obediencia, los recibáis y llevéis a la dicha isla de San Juan, y allí se encomienden a los vecinos por naborías se casa, como las otras naborías de la dicha isla [...]". ${ }^{21}$

Esta no es más que una muestra de que los caribes hacían presos a muchos autóctonos de la isla de San Juan, los taínos. Y es por ello que ven en estas personas, que pudieron haber sido objeto de sometimiento por parte de 
las poblaciones caribes, como poblaciones que accederían de buen grado a ir con las tropas castellanas y hacer la guerra contra los caribes, como un enemigo común. Siendo llevados de nuevo a San Juan donde serían repartidos en las diferentes casas.

Pero no solo los caribes hicieron la guerra contra los colonos, también hay documentos donde se especifica que las propias gentes de San Juan se rebelaron contra las tropas colonizadoras. Según algunos documentos, como veremos a continuación de 1512, se hace mención a este hecho, haciendo mención también que las gentes autóctonas de la isla estaban siendo esclavizadas. No con un carácter temporal, sino de por vida, algo que no estaba contemplado como legal.

"Don Fernando [...] tenemos mandado que por el tiempo que nuestra voluntad fuese todos los indios que fueren tomados de buena guerra en la isla de San Juan por los vecinos y otras personas della, sean y queden por esclavos de los que los tomaren, y porque yo he sido informado que en lo susodicho se hacen muchos fraudes $y$ tienen por esclavos otros indios diciendo, que son tomados de buena guerra y dellos con su inocencia no saben alegar su derecho [...] por la presente, es mi merced y voluntad y mando que todos los indios que desde el día que ésta, mi carta, fuere pregnada en la dicha isla de San Juan en adelante fueren tomados de buena guerra en la dicha Isla por los vecinos y otras cualquiera personas della, sean naborías de los que los tomaren y los tengan y los sirvan dellos [...] que no sean esclavos $[\ldots]^{\prime \prime} .^{22}$

En este fragmento se puede leer que los vecinos de la isla si estaban tomando como esclavos a los indios pero se deja dicho que eso no era legal. Por lo que se deja dicho que a partir del momento de la llegada esta carta los indios capturados en la buena guerra no podían ser esclavos, sino que por el contrario, debían ejercer en las naborías para el beneficio de los vecinos y vecinas de la isla.

En las primeras décadas de la colonización, ya se puede observar, mediante el análisis de los diferentes documentos que nos hemos encontrado, 
que la población autóctona de estas islas iba teniendo un trato especial y que existían debates en torno a la posibilidad de que fuese posible evangelizarlos y que de esta forma formasen parte de la Iglesia Católica. Es por esta razón que el rey Fernando el Católico en 1513 redacta una serie de ordenanzas para el buen trato de los indios, para ser tratados como los y las españolas que vivían en la isla: ${ }^{23}$

"Primeramente, ordenamos y mandamos que por cuanto es nuestra determinación de mudar dichos indios y hacerles estancias junto con la de los españoles [...]"

"Asimismo ordenamos y mandamos que el vecino a quien encomendare los dichos indios, sea obligado a les tener hecha una casa para la iglesia juntamente con la hacienda [...] en la cual dicha iglesia ponga imágenes de Nuestra Señora y una campanilla para los llamar a rezar [...] todos juntos decir el Ave Maria y el Pater Noster y el Credo y Salve Regina [...]"

"Ordenamos y mandamos que cada uno que tuviere cincuenta indios o donde arriba encomendados, sean obligados a hacer mostrar un muchacho, el que más hábil dellos les pareciere, a leer y a escribir las cosas de nuestra fe para que aquellos muestren después a dichos indios $[\ldots]^{\prime \prime}$

Esto es solo una pequeña muestra de una serie de reglamentos que tiene un total de 35 leyes en las cuales se hace un especial hincapié en la necesidad de evangelizar a estas poblaciones, para expandir la fe católica. También se menciona la necesidad de enseñar a escribir y leer, ya que es esencial conocer la lengua para que esta evangelización sea efectiva. Se hace una mención especial a la alimentación que se les debía dar así como al alojamiento mientras están bajo la encomienda, ya que son una responsabilidad directa del encomendero. Especificando que estos indios que están en encomiendas no solo pueden trabajar en las tierras de los encomenderos, sino que una tercera parte de estos indios deben trabajar en las minas del reino. Es definitiva un compendio de leyes en las cueles se especifica cómo deben ser tratados estos indios y como se debe hacer uso de ellos. 
Además existen otros ejemplos de que los colonos tuvieron una relación muy cercana a la población indígena de la isla. En la Real Cédula a Don Diego Colón a los jueces de la Isla Española, se le da licencia a cualquier persona natural de los reinos de Castilla, residente en la isla, para que puedan casarse con indias naturales de aquella. ${ }^{24}$ Algo que solo se puede entender si se tiene en cuenta que la población mayoritaria que viajaba al "Nuevo Mundo" eran hombres y que las mujeres que viajan lo hacían junto a sus maridos o eran de familias pudientes. Esta posibilidad de casarse con mujeres autóctonas de la isla nos demuestra que había una cercanía entre ambas poblaciones.

Por lo tanto, entre la disminución de la población india de la isla por los diversos motivos que se han mencionado con anterioridad se debe añadir que se estaban llevando a cabo leyes que protegían y equiparaban a la población india con los venidos de la Península lbérica, la necesidad de un suministro de mano de obra esclava era cada vez más imperante.

\section{Población esclava traída de la Península Ibérica a la isla de San Juan Bautista}

En estas primeras décadas, en la isla de San Juan, también podemos encontrarnos esclavos y esclavas llevados desde la Península lbérica a través de licencias. La esclavitud durante el siglo XVI en la isla de San Juan tuvo un recorrido diferente al que se supone que existía en siglos posteriores. El tráfico negrero no estaba implementado como el sistema predilecto para abastecer a las islas del Caribe de mano de obra esclava, sino que esto se llevaría a cabo más adelante. ${ }^{25}$

En diferentes documentos encontrados en el Archivo General de Indias sobre los esclavos y esclavas que fueron llevadas a San Juan por Juan Ponce de León entre 1511 y 1514 se pueden observar varios aspectos que nos ayudan a comprender qué condiciones se necesitaban que tuviesen estos esclavos y esclavas para pasar a las islas durante estas primeras décadas.

Después de analizar los documentos que he encontrado se hace patente que existen una serie de condiciones que tienen que cumplir estas personas esclavizadas para poder ser llevadas a tierras del Nuevo Mundo. Poniendo 
de este modo, en las primeras décadas del siglo XVI, limite al movimiento de esclavos y esclavas entre continentes ya que lo que se buscaba no era mano de trabajo.

Uno de los requisitos indispensables que debían tener estas personas esclavizadas era la de ser cristianos. Debían ser personas cristianizadas y que procediesen de la Península lbérica, es decir, que hubiesen nacido o que hubiesen vivido en la Península. Esta es una forma de acreditar que todas las personas que habitaban en la isla eran de la religión católica, sin temor a que se extendiese por la isla religiones que no eran cercanas a la Corona.

Un ejemplo de esto lo encontramos en una licencia de 1514 que se le concede a Juan Ponce de León para pasar esclavos de España a la isla de San Juan. En esta licencia se especifica que estas personas son dos hombres y dos mujeres, que viven como cristianos desde hace cuatro años, lo que significa que no nacieron con esta religión sino que se convirtieron ya sea por la fuerza o por voluntad propia. Esto nos puede hacer pensar que fueron llevados desde algún lugar fuera de la Península lbérica en el que no se profesase la religión católica y que hubiesen sido comprados y vendidos en los puertos españoles o, por el contrario, que sí hubiesen nacido en la Península y que por tanto fusen personas moriscas, que tras la Conquista de Granada, se les obligase a convertirse al cristianismo y fuesen capturados como esclavos. ${ }^{26}$

Otro ejemplo de ello es la licencia de esclavos que se le da a Juan Ponce de León en 1512 en la cual se especifica: "Juan Ponce de León puede pasar tres esclavos y tres esclavas cristianos a la isla de La Española" ${ }^{27}$ En esta licencia en el que se especifica que estos esclavos van a servir a su hijo Luis Ponce de León, también se deja constancia de que estas personas son cristianas, parece ser un requisito indispensable para dar la licencia necesaria para transportar a estas personas al "Nuevo Mundo".

El siguiente aspecto que se destaca y parece ser de gran importancia para la concesión de la licencia, es que estas personas esclavas sean para el servicio personal del dueño y la dueña. Parece que durante las primeras décadas del siglo XVI se estaba limitando el número de esclavos y esclavas externos a la isla, imponiéndoles la necesidad a los amos de que estas personas esclavas estuviesen destinados a un servicio personal, dedicados 
al hogar, al servicio más cercano a sus dueños y propietarios. No beneficiándose de su venta en la isla.

En varios documentos se expresa y se jura, que los esclavos y esclavas que se llevan a la isla son para el servicio personal de Juan Ponce de León o de su hijo Luis Ponce de León. En una Real Cédula se deja constancia de que Pedro Moreno, en nombre de Juan Ponce de León, pasa a la isla una esclava para servicio de la casa de éste, dando juramento de que es cristiana y de que se la entregará a éste cuando llegue a puerto. Esta Real Cedula es de $1511 .^{28}$

Parece que mediante los repartimientos y las naborías son los indios taínos y caribes los que hacen un trabajo más duro en la isla de San Juan, ya que trabajan en las minas sacando el poco oro que había y en las tierras. El tráfico de esclavos que había de fuera del Caribe era mínimo y se hacía con cuidado, eligiendo las personas que iban a entrar y el trabajo que iban a realizar. A esto se le añade que el traer esclavos y esclavas de la Península debía ser costoso, ya no solo por el viaje, y por la dificualtad que suponía que concediesen las licencias necesarias. Sino por el hecho de que la población esclava en la Península no es muy numerosa. Estas personas esclavas, en la isla de San Juan, se puede presumir que su tenencia se consideraba un bien para privilegiados y para gente con cierto nivel adquisitivo y estatus.

En los documentos que se han podido analizar no existe una diferencia en el sexo entre las personas que eran llevadas a las islas desde la Península Ibérica como esclavos. Había tanto hombres como mujeres, no concediendo predilección por ninguno de los sexos. Tanto hombres como mujeres eran llevados a la isla como esclavos. Ambos eran productivos dentro del sistema esclavista de principios del siglo XVI, ya sea por su oficio o por sus cualidades.

Otro de los aspectos curiosos en estas licencias es que no especifica el color de la piel, parece que no es relevante que tenga la piel negra o blanca, ya que en los documentos que he analizado no se menciona en ningún caso el color de piel de estas personas. No es hasta unas décadas después cuando se va mencionado en varios documentos el color de la piel entre las personas que se traen a la isla.

28 Licencia de pase de esclava a Juan Ponce, (1511), AGI, Indiferente, 418,L.3,F.191V(1). 


\section{Comienzo del tráfico negrero}

Un periodo que podríamos denominar de transición y se puede percibir a través del análisis de la población que existe en la década de los treinta durante el siglo XVI. Comienza a percibirse una masa de población esclava más heterogénea y diversa. Para ello se ha analizado el censo realizado por el Gobernador Francisco Manuel de Lando entre los años 1530 y 1531. El recuento final eran de 332 españoles, indios encomendados 497, indios esclavos 1527 y esclavos negros 2077, además de esclavos cautivos 1030 personas. ${ }^{29}$

Con el análisis de este censo (gráfico 1) podemos ver que existe en la isla de San Juan dos ciudades con una importancia mayor que el resto, San Juan y San Germán. En ambas ciudades los vecinos libres y colonos, es decir, que no eran naturales de la isla y que su procedencia se puede presumir era del Viejo Mundo, más concretamente de la Península lbérica, eran una mínima parte del total de la población de la isla.

Lo que más llama la atención de este censo (gráfico 2) es que hay cada vez más negros y negras esclavizadas que gentes autóctonas del lugar, aunque en estos primeros momentos el número es muy parecido. Esto muestra que las necesidades de los colonos va cambiando y esto puede deberse a varios motivos. Uno de los cuales pude ser que los indios, tanto taínos como caribes, habían sido diezmados, ya sea por las enfermedades que sufrieron tras el contacto con los españoles, una insuficiencia alimentaria - por las guerras que se llevaron a cabo entre los caribes y los colonos. ${ }^{30}$ Ocasionando una necesidad de mano de obra que no podía satisfacerse con únicamente los esclavos y esclavas que eran traídos desde la Península Ibérica. También las plantaciones eran cada vez mayores y por tanto se necesitaba una mano de obra masiva para trabajar en las tierras y en las minas que todavía estaban activas.

Pero otro de los motivos es que se alzaron voces en contra de la esclavización de las poblaciones autóctonas de las islas caribeñas y de tierra firme del continente americano. Con la instauración de la Iglesia Católica en las islas del Caribe, y más particularmente con la Orden de los Dominicos,

29 WATLINGTON, Francisco, (2013), "La tatarabuela: el siglo XVI en Puerto Rico", Revista de Ciencias Sociales, $\mathrm{n}^{\circ}$ 26, pp. 14-29.

30 PICÓ, Historia general de Puerto Rico. 


\section{Censo Gobernador Francisco Manuel de Lando (1530-1531)}

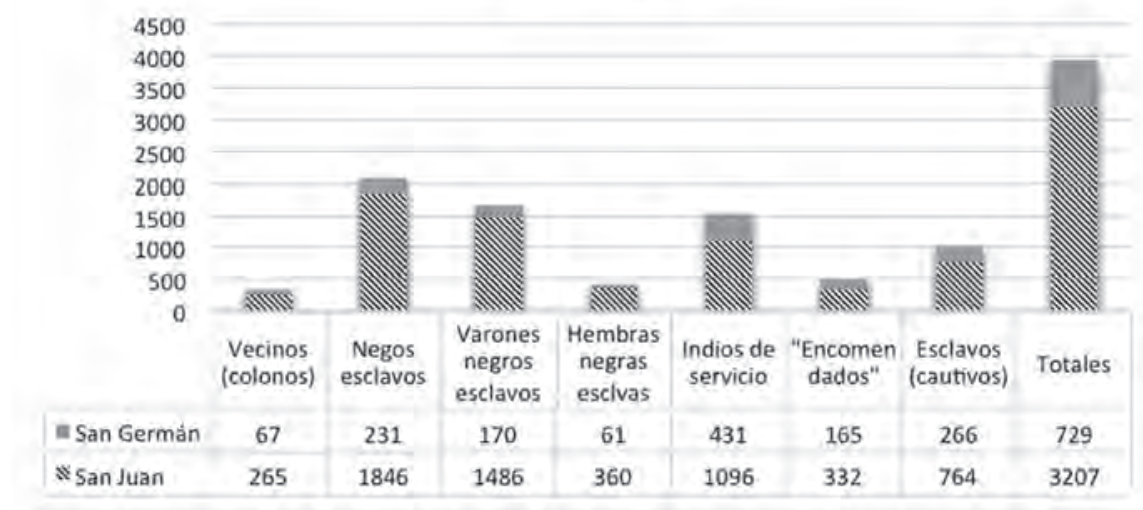

Gráfico 1. Elaboración propia a partir de los datos obtenidos del censo del Gobernador Francisco Manuel de Lando (noviembre de 1530 y marzo de 1531) (WATLINGTON, 2013).

\section{Total de personas en el Censo Gobernador Francisco Manuel de Lando (1530-1531)}

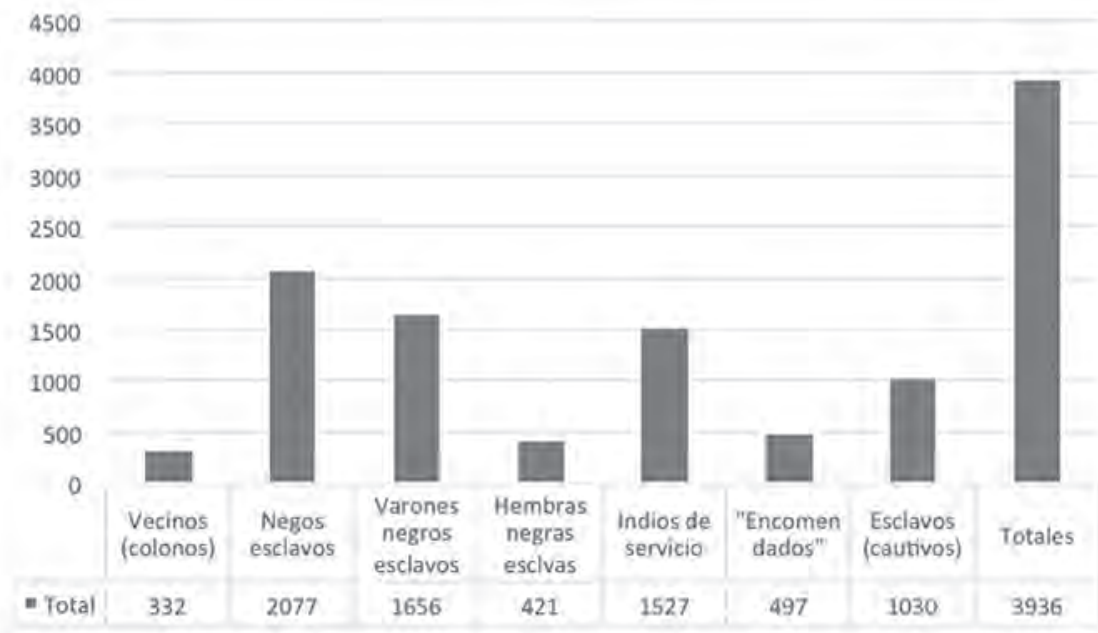

Gráfico 2. Elaboración propia a partir de los datos obtenidos del censo del Gobernador Francisco Manuel de Lando (noviembre de 1530 y marzo de 1531) (WATLINGTON, 2013). 
se produjo una lucha por hacer que las poblaciones de indios de las islas caribeñas, tanto taínas como caribes, fuesen liberadas ya que estaban diezmadas. Aunque el sistema esclavista para algunos juristas y teólogos fuese en contra del derecho a la libertad de las personas, la lglesia y el Estado europeos no se pudieron negar a legislar sobre un sistema productivo instaurado y naturalizado. ${ }^{31} \mathrm{El}$ más mediático de estos debates fue el que se produjo en la Escuela de Salamanca en 1552. Cabe destacar que este movimiento no va contra la esclavización ni contra el Estado, sino que se debatía sobre quienes debían ser sometidos y quienes no, para suplir y abastecer de mano de trabajo esclava a ese sistema. ${ }^{32}$ Entre los que participaron en este debate estaban Fray Bartolomé de las Casas a favor de la no esclavización de las poblaciones amerindias y Juan Ginés de Sepúlveda, teólogo y doctor a favor de la esclavización de estas poblaciones. Bartolomé de las Casas, expone en uno de sus escritos: ${ }^{33}$

"En cuanto a los indios, porque están muy destruidos y muy flacos [...] no an dejado los cripstianos sino ocho o nueve mil [...] hecer mercedes en serbirse dellos como de libres y vasallos suyos [...] haga merced a los cristianos, que agora están en las yslas, que pueden tener cada uno dos esclavos negros y dos negras $[\ldots]^{\prime \prime 34}$

Es en este documento se pone de manifiesto que la esclavitud de la población indígena de las islas del Caribe debería estar prohibida. Aunque no es menos cierto que estas poblaciones siguieron trabajando como casi-esclavos para los conquistadores durante un periodo de tiempo bajo condiciones infrahumanas, lo que se conocía como naboríos o naborías. Y esto se debe, principalmente a que la esclavitud no es algo de lo que se pueda prescindir. Por lo tanto estas naborías son una solución a esa deficiencia de mano de trabajo. Esta necesidad les llevó a la conclusión que la mejor forma de suplirla era mediante la traída de personas desde continente africano.

31 DÍAZ SOlER, Historia de la esclavitud negra en Puerto Rico.

32 MINGORANCE y ABRIL, La esclavitud en la Baja Edad Media.

33 COLL, Cayetano, (1972), Historia de la esclavitud en Puerto Rico: (información y documentos). Compilación de Isabel Cuchi Coll. Sociedad de Autores Puertorriqueños, San Juan de Puerto Rico.

34 Fray Bartolomé de las Casas: apaciguamiento de indios. (1516). AGI, 252,R.2 
La introducción de población esclava proveniente directamente de África y en mayor cantidad que anteriormente se comenzó a producir a partir de la década de 1520. Este tráfico negrero se llevó a cabo por la falta de mano de obra indígena esclava y por el creciente sentimiento de proteger a las poblaciones indígenas isleñas que habitaban en el Caribe. ${ }^{35}$

Todo esto provoca que la forma en la que se introducen personas esclavizadas a la isla de San Juan, y al Caribe en general, va cambiando, y se hace evidente cuando encontramos varios documentos en los que la descripción de las personas que se traen va variando en comparación con las primeras que ya habíamos mencionado y encontrados de la primera década del siglo XVI. La Cedula Real de 1534 concedida a Cristóbal Ponce de León podemos leer: "El Rey, para Don Cristóbal Ponce de León de veinte esclavos negros". ${ }^{36}$ En este documento no se especifica el sexo de las personas que se van a llevar como esclavos a la isla, que tipo de trabajo van a realizar o si están cristianizados. Eso comienza a no ser importante para las autoridades que regulan este tráfico esclavista, la Casa de Contratación. En lo que si se especifica es el color de la piel, se dice que son negros. Es el comienzo de lo que se denominaría el tráfico negrero. Personas que son capturadas en África con el único propósito de servir como esclavos y esclavas.

Otro documento que hace referencia a la traída de esclavos negros a la isla es de 1544 teniendo como beneficiario a García Ponce de León, en el cual ocurre lo mismo que en anterior. No se especifica ni sexo ni religión que profesan estas personas. ${ }^{37}$ En el que se le da licencia para llevar a la isla tres esclavos negros, aquí sí dejando constancia que van a servir bajo su persona.

En uno de los documentos que he analizado, la Real Cédula de 1560, dice así:

"Juan Ponce de León, alcaide de la fortaleza de la ciudad de Puerto Rico, nieto de Juan Ponce de León, colonizador de la isla de San Juan. Se le autoriza ir a las Canarias, desde donde puede tomar al-

35 COLL, Historia de la esclavitud en Puerto Rico.

36 Real Cédula a Cristóbal Ponce de León, dándole licencia para llevar a Indias 20 esclavos negros, pagando los derechos correspondientes, (1534). AGI. Indiferente, 422,L.16,F.102V(3).

37 Real cédula a García Ponce de León, dándole licencia para pasar a Indias 3 esclavos negros para su servicio, (1544). AGI. Indiferente, 423,L.20,F.750R(1). 
gún navío que vaya para Indias, y llevar consigo los 11 esclavos de que se le han dado licencia pero con la condición de que los registre antes en Sevilla". ${ }^{38}$

Es un ejemplo en el que las personas que se trasladan a la isla de San Juan provienen de fuera de la Península ya que se deben registrar en Sevilla para poder trasladarlos. No se especifica el color de la piel, como hemos visto en el caso anterior. Tampoco se describe el sexo de las personas y cuál es su religión. La ambigüedad de la información nos da una idea de que las características de estas personas que son trasladadas al "Nuevo Mundo" como fuerza de trabajo para este sistema esclavista de producción ya no es tan importante, lo importante es su trabajo, que sean productivos sin importar su religión o su sexo, e incluso su color de piel. Ya no se prima la evangelización de la isla, sino su productividad.

El último documento que se puede considerar de relevancia para este análisis es la Real Cédula dando licencia a Luis Ponce de León para "pasar a las Indias cuatro esclavos negros para su servicio". ${ }^{39}$ En este documento se sigue sin especificar la religión de las personas que se trasladan, siendo este un claro ejemplo de que la religión de estas personas no era tan importante como en un inicio.

Parece que el sistema productivo esclavista ya comienza a sustentarse en el tráfico esclavista, es cierto que en ninguno de los casos anteriores el número es muy elevado, y que en algunos de estos documentos se especifica que van a estar bajo el servicio del propietario. Pero, si abrimos un poco más la mirada y observamos otros documentos se puede ver una realidad que nos acerca a un sistema de producción cada vez más sustentado en el tráfico negrero. El documento que puede dar un poco de luz es el que hace referencia a la Virreina Doña María de Toledo casada con Diego de Colón, hijo de Cristóbal Colón. Mediante su análisis se puede observar que las licencias para llevar un número cada vez más elevado de personas esclavas a la isla de San Juan en particular y de las islas del Caribe en general se va normalizando. En este documento de 1534 se le da permiso a María de Toledo para llevar 100 esclavos, para las granjerías de las islas La Española, San Juan, Cuba y Jamaica. Aquí no es importante el que no

38 Real cédula a Juan Ponce de León, (1560). AGI, Indiferente, 425,L.23,F.469V-470R.

39 Real Cédula dando licencia a Luis Ponce de León para pasar a Indias 4 esclavos negros para su servicio. (1561). AGI, Indiferente, 425,L.24,F.41V. 
se especifique el sexo ni la religión, sino el número tan elevado de personas que se mueven para la producción esclavista de estas islas. En ningún documento analizado con anterioridad la cantidad de personas había sido tan elevado.

\section{Conclusiones}

Por lo tanto, y a modo de conclusión, se puede decir que el sistema de producción de la isla se vio influenciado por el sistema esclavista que estaba viviendo Europa y, más concretamente, España en ese momento. Ya que este no era un sistema que estuviese muriendo en absoluto, sino que se encontraba en un buen estado de salud. Era un sistema que producía mucha riqueza con un bajo costo. Es por ello que este sistema fue el que se instauró en las nuevas tierras "descubiertas" por Colón y, en el caso de la Isla de San Juan, colonizada más tarde por Juan Ponce de León.

Un sistema que se beneficiaba en un primer momento de los indios autóctonos de las islas, haciéndolos esclavos a través de las guerras. Su estatus fue cambiando a lo largo de las primeras décadas del siglo XVI, por la oposición y alegatos de teólogos y juristas, junto con el beneplácito de la Corona, para que estas personas comenzaran a estar bajo el servicio de colonos y caciques durante un tiempo determinado de tiempo, siendo posteriormente libres, mediante naboríos y repartimientos de Indios $\mathrm{A}$ esto se le une las pocas licencias que se concedían para pasar esclavos y esclavas a la isla desde la Península lbérica, convirtiéndose en un "objeto" de lujo y privilegio. Además estas personas tenían que tener una serie de características para hacerlos aptos. Entre estas estaba el ser cristianos y que trabajasen al servicio de su dueño. El color de la piel no es importante y se deja constancia si son hombres y mujeres. Se tenía una minuciosa descripción de toda persona que entraba en la isla.

Pero lo cierto, es que el sistema esclavista va cambiando en poco más de dos décadas, y esto se hace perceptible. Durante el primer siglo que dura la colonización de la isla su economía se sustentaba en las grandes plantaciones, lo que provoca que la necesidad de mano de trabajo esclava sea necesaria. La población taína y caribe se había reducido en gran 
medida y su posición como esclavos y esclavas era solo temporal, a esto hay que añadir que los esclavos y esclavas que procedían de la Península no era suficiente. Por lo que, llegó un momento, en el que estas licencias se concedieron dejando de lado los dos requisitos que se habían hecho imprescindibles en las primeras décadas, la religión que procesaban y que su ocupación estuviese bajo el servicio directo del propietario o propietaria, mirando hacia el África subsahariana como lugar para abastecerse de personas. La esclavitud se estaba convirtiendo en un proceso global, se estaba convirtiendo en un negocio que acabaría destrozando millones de vidas. 